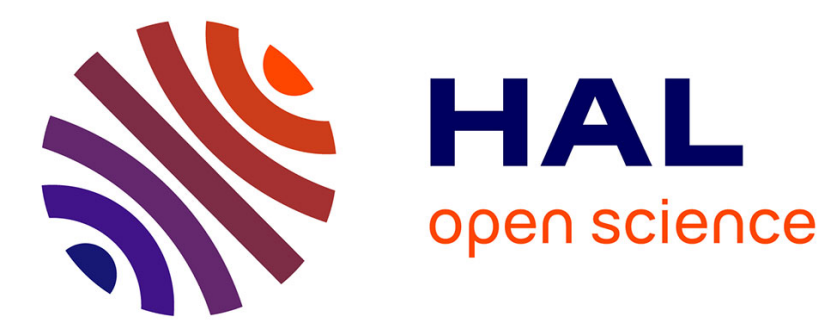

\title{
Ischemic-type biliary lesions: A leading indication of liver retransplantation with excellent results
}

Astrid Schielke, Olivier Scatton, Pierre-Yves Boelle, Fabiano Perdigao, Denis Bernard, Olivier Soubrane, Filomena Conti

\section{- To cite this version:}

Astrid Schielke, Olivier Scatton, Pierre-Yves Boelle, Fabiano Perdigao, Denis Bernard, et al.. Ischemictype biliary lesions: A leading indication of liver retransplantation with excellent results. Clinics and Research in Hepatology and Gastroenterology, 2019, 43, pp.131 - 139. 10.1016/j.clinre.2017.11.005 . hal-03486284

\section{HAL Id: hal-03486284 \\ https://hal.science/hal-03486284}

Submitted on 20 Dec 2021

HAL is a multi-disciplinary open access archive for the deposit and dissemination of scientific research documents, whether they are published or not. The documents may come from teaching and research institutions in France or abroad, or from public or private research centers.
L'archive ouverte pluridisciplinaire $\mathbf{H A L}$, est destinée au dépôt et à la diffusion de documents scientifiques de niveau recherche, publiés ou non, émanant des établissements d'enseignement et de recherche français ou étrangers, des laboratoires publics ou privés.

\section{(ㄷ)(1) $\$$}

Distributed under a Creative Commons Attribution - NonCommerciall 4.0 International 


\section{Ischemic-Type Biliary Lesions: A leading Indication of Liver Retransplantation with Excellent Results}

Astrid Schielke, $M D^{1}$, Olivier Scatton, $\mathrm{MD}, \mathrm{PhD}^{1,2}$, Pierre-Yves Boelle, $\mathrm{MD}, \mathrm{PhD}^{2,3}$, Fabiano Perdigao, $\mathrm{MD}^{1}$, Denis Bernard, $\mathrm{MD}^{4}$, Olivier Soubrane, MD, $\mathrm{PhD}^{5,7}$, Filomena Conti, MD, $\mathrm{PhD}^{2,6}$

1 AP-HP, Hôpital Pitié-Salpêtrière, Servie de Chirurgie Digestive et Transplantation hépatique, 47-83 boulevard de l'Hôpital, F-75013, Paris, France

2 Sorbonne Universités, UPMC Université Paris 06, 4 Place Jussieu, F-75005, Paris, France

3 AP-HP, Hôpital Saint-Antoine, Department of Public Health, 184 Rue du Faubourg Saint-Antoine, F75012, Paris, France

4 AP-HP, Hôpital Pitié-Salpêtrière, Department of Anesthesiology, 47-83 boulevard de l'Hôpital, F75013, Paris, France

5 AP-HP, Hôpital Beaujon, Servie de Chirurgie Digestive et Transplantation hépatique, 100 Boulevard du Général Leclerc, 92110 Clichy, France

6 AP-HP, Hôpital Pitié-Salpêtrière, Unité de Transplantation Hépatique, 47-83 boulevard de l'Hôpital, F-75013, Paris, France

7 Université Paris 07, 5 Rue Thomas Mann, F-75013 Paris, France

\section{Corresponding Author:}

Professor Olivier Scatton, MD, PhD,

Servie de Chirurgie Digestive et Transplantation hépatique, Hôpital Pitié-Salpêtrière, Assistance Publique-Hôpitaux de Paris (AP-HP), 47-83 boulevard de l'Hôpital, 75651 Paris Cedex 13, France ; Phone: +33.142.17.56.90, Fax: +33.142.17.56.89, E-mail: olivier.scatton@aphp.fr

Text word count: 3332

\section{Tables: 5}

\section{Figures: 3}


Abbreviations: LT, liver transplantation; RLT, liver retransplantation; ITBL, ischemic-type biliary lesion; PNF, primary non-function; HAT, hepatic artery thrombosis; CMV, cytomegalovirus; MRI, magnetic resonance imaging; ERCP, endoscopic retrograde cholangiopancreatography; ICU, intensive care unit.

This work did not receive any form of grant. The authors declare no conflict of interest. 


\section{Abstract}

Background: Liver retransplantation (RLT) is the only life-saving treatment option for patients with a failing graft, but it remains a major challenge because of inferior outcomes and technical difficulties. Methods: This study aimed to evaluate the outcomes of and risk factors for adult RLT in a single center, focusing on the etiology of graft failure. Between 1987 and 2011, 1592 liver transplants (LTs) and 143 RLTs (9\%) were performed at our institution. Results: The 1-, 5- and 10-year patient survival rates after RLT were 60\%, 52\% and 39\%, and the graft survival rates were $55 \%, 46 \%$ and $32 \%$. The 90 -day mortality rate was $32 \%$, mainly due to septic complications ( $45 \%$ of deaths). Ischemic-type biliary lesions (ITBL) were the leading indication for RLT (23\%), and patient survival was significantly better in patients retransplanted for ITBL than for any other indication $(p<0.02)$. Indications other than ITBL $(p=0.015)$, the transfusion of more than 7 units $(p=0.006)$ and preoperative dialysis $(p=0.005)$ were the three parameters associated with poor survival after RLT. Conclusion: Patients with ITBL benefit the most from elective RLT.

\section{Abstract word count: 177}

Key words: liver retransplantation, ischemic-type biliary lesion, performance status, organ shortage 


\section{Introduction}

Liver transplantation (LT) has become an established therapy for end-stage liver disease, enabling one-year survival rates higher than $80 \%$ in experienced centers [1-3]. In the event of graft failure, liver retransplantation (RLT) is the only life-saving option, corresponding to $5 \%$ to $22 \%$ of total LT activity in most countries, including in Europe and the USA [1-3].

The results of RLT are significantly worse than those of primary LT: patient survival is $20 \%$ lower at both 1 and 5 years $[3,4]$. Because of the increasing shortage of liver grafts (about one graft for two potential recipients in most western countries), in-depth discussions are necessary in order to determine whether certain RLT subgroups might have a better prognosis and stronger indication than others which could unfortunately be considered as "futile" indications for LT.

Although several series have been reported $[1,3,5,6]$, outcomes as a function of indication are still poorly defined because of the lack of reports focusing on the postoperative and longterm outcomes of RLT. The principal late indications for RLT are recurrent liver diseases, currently dominated by HCV recurrence and ischemic-type biliary lesions (ITBL), whereas early indications remain primary graft non-function (PNF) and hepatic artery thrombosis (HAT). However, over time, PNF and HAT have become marginal indications for RLT, and recurrent hepatitis $C$ is now easily cured using direct antiviral agents. It is therefore likely that ITBL will become the leading indication for RLT in the near future, and it is wise to determine whether it is a useful indication for RLT. This retrospective study of the experience of a single large center in Europe thus compared the respective results of different indications for RLT over three different periods, in terms of long-term patient and graft survival. 


\section{Patients and Methods}

Between 1984 and 2011, a total of 1592 LTs were performed at Cochin and Saint Antoine Hospitals in Paris (by the same surgical and medical teams). In this population, 143 RLTs (9\%) were performed in patients $>16$ years as from 1987 and were included in this retrospective analysis. Fourteen patients had initially been transplanted in childhood (age <16) and undergone a subsequent RLT in adulthood. All patients received a full-size organ, except for four patients who received full left liver grafts, with one from a living-related donor. There were no non-heart beating donors in this series. The three periods studied ran from 1987 to 1994 (P1), from 1995 to 2004 (P2) and from 2005 to 2011 (P3).

Pre-, intra- and postoperative data on the recipient were collected regarding age, gender, blood group (recipient and graft), cytomegalovirus (CMV) status, immunosuppression prior to RLT, graft type, transfusion requirements, veno-venous bypass, preoperative dialysis or mechanical ventilation, cold ischemia time, technical aspects (types of caval, portal, arterial and biliary anastomoses) and postoperative complications (arterial, portal, caval, biliary and digestive). The donor data analyzed included age, gender, blood group and CMV status. Surgical techniques in LT and RLT have undergone several changes over time. The piggyback technique for caval anastomosis has been used by our team since 1995. A temporary end-toside portocaval shunt is widely performed during transplantation, except for recipients with significant spontaneous shunts. End-to-end portal, arterial and biliary anastomoses are subsequently performed. Veno-venous bypass is used in the event of difficult dissection, unstable patients in the case of cava replacement, and in the absence of spontaneous shunts and hemorrhage in the context of portal hypertension. 
The medical management of transplant recipients has also evolved over time. Before 1995, patients received cyclosporine, while after that time, their immunosuppressive therapy included tacrolimus and mycophenolate mofetil. Throughout the study period, the basic immunosuppressive regimen included low doses of prednisolone that were tapered and usually discontinued 6 months after RLT, except in patients with autoimmune liver disease (receiving prednisone $5 \mathrm{mg} / \mathrm{d}$ lifelong). Doses were adapted to maintain blood levels of cyclosporine between 100 and $300 \mathrm{ng} / \mathrm{ml}$ and of tacrolimus between 8 and $15 \mathrm{ng} / \mathrm{ml}$. Patients who were CMV-positive prior to RLT, or CMV-negative patients receiving a CMVpositive graft, were administered CMV prophylaxis (aciclovir until 2000, ganciclovir until 2005 and then valganciclovir), which was maintained for 3 or 6 months in the absence of any contraindications or confirmed ongoing clinical CMV infection. Since 2008, all patients have routinely received acetylsalicylic acid $(100 \mathrm{mg} / \mathrm{d})$ to prevent arterial thrombosis as soon as their platelet count reaches $50 \times 10^{9} / \mathrm{I}$, in the absence of any hemorrhagic manifestations.

The diagnosis of ITBL was based on non-anastomotic intrahepatic bile duct strictures, patency of the hepatic artery and repeated episodes of cholangitis without histological signs of recurrent PSC or rejection. New diagnostic tools such as magnetic resonance imaging (MRI) and endoscopic retrograde cholangio-pancreatography (ERCP) have become available over time and enabled the more detailed diagnosis and management of vascular and biliary abnormalities during LT follow-up. The diagnosis of ITBL by means of recent non-invasive and endoscopic methods has certainly contributed to a more precise definition of this emerging indication.

The MELD score was introduced in France in 2007. Liver graft allocation was initially managed between 1994 and 2004 using a center-based national allocation system. As from 
2004, liver graft allocation was based on a national nominal waiting list. Exceptional national priority is given to candidates presenting with primary non-function (PNF) or hepatic artery thrombosis (HAT) during the first seven days after their initial LT. After these seven days, the allocation of liver grafts to RLT candidates follows the same rules as those which apply to candidates for primary LT [7].

\section{Statistical analysis}

For the present study, categorical variables were compared across samples using the chisquared test, while quantitative variables were compared using the Wilcoxon test. Overall survival was defined using the time elapsing between the first RLT and death. Graft survival was defined as the time from the first RLT to death or the second RLT, whichever occurred first. Patients alive after RLT were censored for death at the time of the last news on their case. A Kaplan-Meier analysis was used to estimate survival. The Cox proportional hazard model was used to test for the influence of co-variables on survival. For comparisons of survival as a function of the indications for RLT or the severity of the recipients, we used the Bonferroni-Hochberg method to adjust for multiple comparisons (six comparisons). Multiple imputation was used for missing variables. All reported $p$-values are two-sided. We concluded a significant difference at $p$-values smaller than 0.05. All computations were performed using R software. 


\section{Results}

\section{Study population}

Among the study population of 143 patients over 16 years that were retransplanted, representing $9 \%$ of our activity, there were 93 men and 50 women, with a median age of 45 years (IQR $[32,53])$. Twelve patients underwent a second RLT, and two a third RLT. Eight retransplanted patients received combined liver-kidney transplants. The median required volume of intraoperative PRBCs was 7 units (range: 0 to 145 units). The mean cold ischemia time did not change significantly over time.

The indications for primary LT and RLT are detailed in Table 1. The characteristics of the principal indications are summarized in Table 2. We examined different periods (P1, P2, P3) and some significant changes occurred over time, as summarized in Table 3. The donors were significantly older in P3, with a median age of 37 years in P1 compared to 46 years in P3 $(p=0.02)$. The indications for RLT changed over time, with primary non-function (PNF) decreasing from $31 \%$ in $\mathrm{P} 1$ to $12 \%$ in $\mathrm{P} 3$, and ITBL increasing from $10 \%$ in $\mathrm{P} 1$ to $29 \%$ in $\mathrm{P} 3$ ( $p=0.016)$. Consequently, in P1, the median time elapsing between LT and RLT was 14 days (range: 5 to 161 days), while in P2 it was 132 days (range: 12 to 852 days), and in P3 228 days (range: 21 to 3649 days) $(p<0.001)$.

Immunosuppressive regimens prior to RLT have changed over time. Cyclosporine A was given to $46 \%$ of LT recipients during P1, while standard triple immunosuppressive therapy based on prednisone, mycophenolate mofetil and tacrolimus was used in $72 \%$ of recipients during P3 (Table 3). Surgical techniques for LT and RLT have also evolved over time (Table 3). Classic end-to-end caval anastomosis was performed in all recipients during the early years of our experience, and the piggyback technique with side-to-side caval anastomosis was performed 
in almost one third of our patients in recent years (Table 3). Biliary anastomosis was performed with a Roux-en-Y loop in $48 \%$ of cases $(n=69)$, and duct-to-duct anastomosis in $30 \%(n=44)$. An arterial conduit on the aorta for arterial reconstruction was performed in $39 \%$ of all cases $(n=47)$. A veno-venous bypass was required during RLT in $39 \%$ of recipients $(n=47)$.

\section{$\underline{\text { Morbidity and Mortality }}$}

Recipient survival rates after RLT were 60\%, 52\%, and 39\% at 1 year, 5 years and 10 years, respectively, while graft survival were $55 \%, 46 \%$ and $32 \%$ at 1 year, 5 years and 10 years, respectively (Fig. 1). Survival rates at 1,5 and 10 years as a function of the different indications were $91 \%, 83 \%$ and $56 \%$, respectively, for ITBL; $63 \%, 48 \%$ and $48 \%$ for chronic rejection; $56 \%, 56 \%$ and $41 \%$ for HAT; $44 \%, 37 \%$ and $32 \%$ for PNF; $36 \%, 24 \%$ and $24 \%$ for recurrent disease, and 56\%, 43\% and 34\% for other indications (Fig. 2). Regarding the different indications for RLT, survival was significantly better in patients retransplanted for ITBL than in those who were retransplanted for any other indication $(p<0.05$, adjusted for multiple testing). The mean time elapsing between LT and RLT was $2.7 \pm 5.2$ years, with intervals ranging from a minimum of $0.4+/-1.4$ years for HAT to a maximum of $3.9+/-5.9$ years for ITBL (Table 2). Follow-up for the different indications after RLT is given in Table 3.

The overall 90 -day mortality rate was $32 \%(n=46)$. The lowest rate was $9 \%$ for patients retransplanted for ITBL and the highest rates were $55 \%$ and $45 \%$ for patients retransplanted for recurrent primary disease and PNF, respectively (Table 2). There was no significant difference in this mortality rate over the different time periods (Table 3). Nearly half of these deaths (48\%) occurred within 7 days of RLT, $30 \%$ within 8 to 30 days and $22 \%$ within 30 to 90 
days. The main causes of death were bacterial infections in $33 \%$ of cases $(n=15)$, fungal infections in $11 \%(n=5)$ and hemorrhage in $13 \%(n=6)$. Multi-organ failure occurred in $13 \%$ of the patients $(n=6)$, and heart failure or brain death in $11 \%(n=5)$. Two hemodynamically unstable patients died intraoperatively (4\%) from reperfusion syndrome. Seven patients (15\%) died for miscellaneous other reasons. The mortality rates at 1 year and 5 years over the three study periods were $46 \%$ and $59 \%$ in $\mathrm{P} 1,33 \%$ and $35 \%$ in $\mathrm{P} 2$ and $42 \%$ and $48 \%$ in P3, without significant difference over time (Table 3).

\section{Prognostic Factors}

Multiple preoperative and intraoperative donor and recipient factors were tested under univariate and multivariate analyses to identify their influence on patient outcomes (Table 4). None of the following was found to exert any significant influence on survival: time interval to RLT, donor-recipient gender mismatch, donor age $>40$ years, cold ischemia time $>12 \mathrm{~h}$, mechanical ventilation prior to RLT, use of veno-venous bypass and duration of RLT. Under univariate analysis, we found that etiologies other than ITBL, such as positive CMV status in a donor or recipient, preoperative dialysis and the intraoperative transfusion of more than 7 units of PRBCs, were associated with impaired survival (Table 4). Under multivariate analysis, only preoperative dialysis and the intraoperative transfusion of more than 7 units of PRBCs were found to be independent factors for survival.

The MELD score was only introduced in France in 2007 and was therefore not available for the majority of the patients covered by this study. To investigate the performance status of the RLT candidates in different indications, we used the percentage of patient who were intensive care unit (ICU)-bound and required mechanical ventilation or dialysis prior to RLT 
(Tables 2 and 3). The survival was significantly reduced in those patients, when compared to those not ICU-bound (Fig. 3), with survival at 90 days, 1 year and 5 years of $55 \%, 48 \%$ and $43 \%$ in ICU-bound patients vs $83 \%, 77 \%$ and $66 \%$, respectively, in the other patients ( $p=$ $0.008)$.

\section{Surgical Complications}

Half of the recipients (55\%) presented at least one surgical complication after RLT (Table 5). The most frequent complications were biliary in $25 \%(n=36)$ and arterial complications in $12.5 \%(n=18)$. Twenty-one of the biliary complications (58\%) occurred on a Roux-in-Y anastomosis. Eleven of the arterial complications (61\%) occurred within 90 days of RLT. Four patients (22\%) died within three months of onset of the complication, two from hemorrhage after arterial rupture and two others from a liver abscess. The proportion of arterial complications remained stable over the three time periods $(p=0.71)$. None of the following factors showed significant influence on the development of biliary or arterial complications: duration of cold ischemia time $(>12 \mathrm{~h}$ ), donor age (>40 years), positive donor CMV serology, presence or absence of transfusion, need or not for veno-venous bypass and type of biliary (duct-to-duct or Roux-in-Y) or arterial (hepatic artery or conduit on the aorta) anastomosis. No cases of arterial thrombosis have occurred after RLT since 2005 . There were seven (5\%) portal vein complications, five of which $(71 \%)$ occurred more than three months after RLT (Table 5). Seven complications (5\%) were seen to affect the vena cava. Three stenoses occurred more than 90 days after RLT and three thromboses occurred within 7 days of RLT. Postoperative bleeding occurred in 20 patients (14\%), six of whom died. Thirteen patients (9\%) presented with digestive complications, all requiring surgical management (Table 5). 


\section{Discussion}

Because the long-term results of RLT show inferior survival rates when compared with primary LT, organ allocation in the context of a growing graft shortage is a broad ethical issue. In this context, it has become crucial to select the best candidates for RLT. This retrospective but large study may help to define the best indications for RLT.

The patient and graft survival rates seen in this series were in line with recent findings in the literature $[1-4,5,6]$. In our series, the vulnerable condition of recipients before RLT was defined by the patients being hospital or ICU-bound because of dialysis or mechanical ventilation. Dialysis support prior to RLT was found to be a significant independent factor predictive of poor survival, as has previously been reported $[3,4,8,9-11]$. There remains an unanswered question as to whether kidneys should be allocated simultaneously to candidates for RLT with renal failure [12-13]. A risk score index has recently identified predictive factors associated with graft failure after RLT [3]. This index includes recipient factors such as age $>55$ years, MELD score $>27$, mechanical ventilation and serum albumin $<2.5 \mathrm{~g} / \mathrm{dl}$ at the time of RLT. In addition, we found that a need for intraoperative transfusion was a strong independent predictive factor for impaired survival, most likely reflecting the technical complexity of RLT. The cutoff ( $>7$ units of PRBCs) was lower than those previously reported, indicating an improvement in the perioperative and surgical management of these patients [3]. In particular, the technical complexity of RLT was also highlighted by the frequent use of a veno-venous bypass. A temporary portocaval shunt was considered and performed whenever possible in order to maintain hemodynamic stability and avoid splanchnic congestion during graft implantation, as reported by other investigators $[8,14]$. 
We observed significant overall mortality (32\%) during the early postoperative course after RLT with great differences among indications, ranging from $9 \%$ for ITBL candidates to $55 \%$ for recurrent disease. Bacterial and fungal sepsis was the main cause of death (45\%) with incidences comparable to those in the literature, ranging from $46.3 \%$ to $62.2 \%[2,3,8,15]$. We also saw important postoperative morbidity, with significant rates of biliary and arterial complications, as known from the literature $[4,16]$. However, it should be noted that after the introduction of acetylsalicylic acid as routine prophylaxis for all our recipients in 2005, we did not observe any arterial thrombosis following RLT. In contrast to the literature, we found that the type of biliary anastomosis (duct-to-duct versus Y-in-Roux) did not influence the rate of biliary complications after RLT [17]. A significant number of digestive complications were observed, affecting $9 \%$ of our patients. This high incidence therefore calls for special attention being paid to this type of complication among recipients in the context of RLT.

However, and in contrast with the literature, no influence on survival was found for variables such as donor age and donor-recipient gender mismatch $[3,8,18]$, , cold ischemia time [8] and the time to RLT [1]. Nor did we find any significant influence on post-RLT outcomes of the time elapsing between primary $L T$ and RLT, which ranged from early $(<7$ days), to intermediate ( $8-90$ days) to late (>90 days). Results in the recent literature are contradictory on this point [3-5]. The definitions of "early", "late", "urgent" or "elective" RLT vary considerably between authors, so that the results may not be entirely comparable.

Rather than the timing of RLT alone, the clinical condition of the RLT candidate and the actual indication for RLT may represent the most important clues to survival. This was suggested as early as in 1999 by a registry analysis [19], but the etiologies of RLT have dramatically changed since that time. The principal late indications for RLT were recently dominated by 
HCV recurrence and ischemic-type biliary lesions (ITBL), whereas early indications remain primary graft non function (PNF) and hepatic artery thrombosis (HAT). Over time, PNF and HAT have become marginal indications for LT, and recurrent hepatitis $C$ is now easily cured direct-acting antiviral agents. This new therapy may indeed open the way towards a change in the management of future RLT candidates, and significantly affect indications and outcomes.

In our study, we showed that survival was significantly better in late elective cases of ITBL than in early urgent cases such as HAT and PNF. In the recent literature, ITBL has become a more frequent indication for RLT. This evolution may reflect the fact that better diagnostic tools are now available to enable accurate diagnosis and early management [20-23]. Patients with ITBL develop progressive graft failure despite aggressive treatment with endoscopic and interventional radiology, and mortality without RLT can be as high as $50 \%-100 \%[20,24]$. The multifactorial origin of ITBL is suggested to be both ischemic, genetic and immunological, and bile salt-induced injury is a known risk factor $[21,25,26]$. The role of CMV infection in ITBL remains controversial $[21,22,25]$. In our series, a positive CMV status was a predictive factor for poor survival.

In the current context of a scarcity of liver grafts, the issue of the futility of RLT needs to be addressed. By considering predictive models of outcomes in RLT, as well as individual patient factors, local and national allocation policies, the final decision to list a patient and allocate a graft may be strongly influenced. These models do not take into account waiting list mortality which can equally affect primary LT recipients and RLT candidates, as can random operative and perioperative events $[26,27]$. The known inferior long-term survival of RLT recipients may cause an ethical conflict between an individual patient's benefit in receiving a 
graft for RLT and the scarcity of liver grafts available for primary LT recipients [27]. Patients with ITBL usually have had good and stable graft function for many years, and the findings from our series suggest that this subgroup of patients might greatly benefit from elective RLT and achieve an excellent long-term outcome, but present a high incidence of early mortality from sepsis. These patients are less frequently ICU-bound and therefore require less dialysis and ventilation prior to RLT when compared to other indications. This non-urgent elective status certainly plays a key role in the outcomes of these patients and should be taken into consideration before listing such a patient for RLT. [1,2]. Management should therefore be focused on improving clinical condition in RLT candidates by reducing the level of immunosuppressive therapy in order to preserve renal function and reduce the incidence of postoperative sepsis and opportunistic infections. 


\section{References}

[1] Marudanayagam R, Shanmugam V, Sandhu B, Gunson BK, Mirza DF, Mayer D et al. Liver retransplantation in adults: a single-centre, 25-years experience. HPB 2010; 12: 217.

[2] Azoulay D, Linhares M, Huguet E, Delvart V, Castaing D, Adam R et al. Decision for retransplantation of the liver. An experience- and cost-based analysis. Ann Surg 2002; 236: 713.

[3] Hong J, Kaldas F, Kositamongkol P, Petrowsky H, Farmer D, Markovic D et al. Predictive index for long-term survival after retransplantation of the liver. Analysis of a 26-year experience in a single center. Ann Surg 2011; 254: 444.

[4] Pfitzmann R, Benscheidt B, Langrehr JM, Schumacher G, Neuhaus R, Neuhaus P. Trends and experiences in liver retransplantation over 15 years. Liver Transpl 2007; 13: 248.

[5] Marti J, Charco R, Ferrer J, Calatayud D, Rimola A, Navasa M et al. Optimization of liver grafts in liver retransplantation: A European single-center experience. Surgery 2008; 144: 762.

[6] Maggi U, Andorno E, Rossi G, De Carlis L, Bresadola F, Mazzaferro V et al. Liver retransplantation in adults: the largest multicenter italian study. Plos One 2012;7:e46643

[7] Francoz C, Belghiti J, Castaing D, Chazouillières O, Duclos-Vallée JC, Duvoux C et al. Model for end-stage liver disease exceptions in the context of the French model for end-stage liver disease score-based liver allocation system. Liver Transpl 2011;17:1137

[8] Markmann JF, Markowitz JS, Yersiz H, Morrisey M, Farmer DG, Farmer DA et al. LongTerm Survival After Retransplantataion of the Liver. Ann Surg 1997; 226: 408.

[9] Zimmerman M, Ghobrial RM. When shouldn't we retransplant? Liver Transpl 2005; 11: 14. 
[10] Postma R, Haagsma E, Peeters P, van den Berg A, Sloof M. Retransplantation of the liver in adults: outcome and predictive factors for survival. Transpl Int 2004; 17: 243.

[11] Rosen H, Prieto M, Casanovas-Taltavull T, Cuervas-Mons V, Guckelberger O, Muiesan P et al. Validation and refinement of survival models in liver retransplantation. Hepatology 2003; 38: 460.

[12] Eason J, Gonwa T, Davis C, Sung R, Gerber D, Bloom R. Proceedings of consensus conference on simultaneous liver kidney transplantation. Am J Transplant 2008; 8: 2243.

[13] Ruiz R, Kunitake H, Wilkinson A, Danovitch GM, Farmer DG, Ghobrial RM et al. Longterm analysis of combined liver and kidney transplantation at a single center. Arch Surch 2006; 141: 735.

[14] Muralidharan V, Imber C, Leelaudomlipi S, Gunson BK, Buckels J, Mirza DF et al. Arterial conduits for hepatic artery revascularization in adult liver transplantation. Transpl Int 2004; 17: 163.

[15] Facciuto M, Heidt D, Guarrera J, Bodian CA, miller CM, Emre S et al. Retransplantation for late liver graft failure: Predictors of mortality. Liver Transpl 2000; 6: 174.

[16] Porret P, Hsu J, Shaked A. Late surgical complications following liver transplantation. Liver Transpl 2009; 15: 12.

[17] Sutton ME, Bense RD, Lisman T, van der Jagt EJ, van den Berg AP, Porte RJ. Duct-to-duct reconstruction in liver transplantation for primary sclerosing cholangitis is associated with fewer biliary complications in comparison with hepaticojejunostomy. Liver Transpl. 2014 Apr;20(4):457-63. 
[18] Buis C, Verdonk R, van der Jagt E, van der Hilst C, Sloof M, Haagsma E et al. Nonanastomotic biliary strictures after liver transplantation, part 1: Radiological features and risk factors for earl vs. late presentation. Liver Transpl 2007; 13: 708.

[19] Rosen HR, Madden JP, Martin P. A model to predict survival following liver retransplantation. Hepatology 1999;29:365-370.

[20] Nakamura N, Nishida S, Neff G, Vaidya A, Levi DM, Kato T et al. Intrahepatic biliary strictures without hepatic artery thrombosis after liver transplantation: An analysis of 1,113 liver transplantations at a single center. Transplantation 2005; 79: 427.

[21] Howell J, Gow P, Angus P, Jones R, Wang B, Bailey M et al. Early-onset versus late-onset nonanastomotic biliary strictures post liver transplantation: risk factors reflect different pathogenesis. Transpl Int 2012; 25: 765.

[22] Heidenhain C, Pratschke J, Puhl G, Neumann U, Pascher A, Veltzke-Schlieker W, Neuhaus P. Incidence of and risk factors for ischemic-type biliary lesions following orthotopic liver transplantation. Transpl Int 2010; 23: 14.

[23] Kim H, Lee K, Yi N, Lee H, Choi Y, Suh S et al. Outcome and technical aspects of liver retransplantation:analysis of 25-year experience in a single major center. Transplant Proc $2015 ; 47: 727$

[24] Verdonk R, Buis C, van der Jagt, Gouw A, Limburg A, Sloof M et al. Nonanastomotic biliary strictures after liver transplantation, part 2: Management, Outcome, and risk factors for disease progression. Liver Transpl 2007; 13: 725.

[25] Buis C, Koekstra H, Verdonk R, Porte R. Causes and consequences of ischemic-type biliary lesions after liver transplantation. J Hepatobiliary Pancreat Surg 2006; 13: 517. 
[26] lacob S, Cicinnati V, Dechêne A, Lindemann M, Heinemann F, Rebmann V et al. Genetic, immunological and clinical risk factors for biliary strictures following liver transplantation. Liver Int 2012; 32: 1253.

[27] Biggins SW. Futility and rationing in liver retransplantation: when and how can we say no? J Hepatol 2012; 56: 1404. 
Table 1. Indications for primary LT and RLT

\begin{tabular}{|c|c|c|}
\hline Indications for primary LT & $\mathbf{n}$ & $\%$ \\
\hline Hepatitis C cirrhosis & 28 & 20 \\
\hline $\begin{array}{l}\text { Hepatocellular carcinoma } \\
\text { On viral B disease } \\
\text { On viral C disease } \\
\text { On alcohol-related liver disease } \\
\text { On cryptogenic liver disease }\end{array}$ & $\begin{array}{c}24 \\
6 \\
6 \\
8 \\
4\end{array}$ & 17 \\
\hline $\begin{array}{l}\text { Biliary disease } \\
\text { Primary sclerosing cholangitis } \\
\text { Primary biliairy cirrhosis } \\
\text { Biliary atresia } \\
\text { Byler's disease } \\
\text { Alagille disease } \\
\text { Histiocytosis }\end{array}$ & $\begin{array}{c}22 \\
7 \\
1 \\
7 \\
5 \\
1 \\
1 \\
\end{array}$ & 16 \\
\hline Alcohol-related cirrhosis & 22 & 15 \\
\hline Hepatitis B cirrhosis & 12 & 8 \\
\hline Fulminant hepatitis & 9 & 6 \\
\hline $\begin{array}{l}\text { Metabolic liver disease } \\
\text { Cystic fibrosis } \\
\text { Wilson's disease } \\
\text { Type IV glycogenosis } \\
\alpha 1 \text {-antitrypsin deficiency } \\
\text { Proprionic acidemia }\end{array}$ & $\begin{array}{l}8 \\
3 \\
2 \\
1 \\
1 \\
1\end{array}$ & 5 \\
\hline $\begin{array}{l}\text { Other } \\
\text { Metastasis } \\
\text { Hemangioendothelioma } \\
\text { Amyloid neuropathy } \\
\text { Toxic } \\
\text { Cryptogenic } \\
\text { Autoimmune cirrhosis }\end{array}$ & $\begin{array}{c}15 \\
5 \\
2 \\
1 \\
1 \\
6 \\
3\end{array}$ & 12 \\
\hline \multicolumn{3}{|l|}{ Indications for RLT } \\
\hline Ischemic type biliary lesion (ITBL) & 33 & 23 \\
\hline Hepatic artery thrombosis (HAT) & 25 & 17 \\
\hline Primary non function (PNF) & 29 & 20 \\
\hline Chronic rejection & 24 & 17 \\
\hline Recurrent disease & 11 & 8 \\
\hline $\begin{array}{l}\text { Other } \\
\text { Hyperacute Rejection } \\
\text { Portal thrombosis } \\
\text { Necrotic graft } \\
\text { Acquired Hepatitis B cirrhosis } \\
\text { Undetermined cirrhosis } \\
\text { Intrahepatic Lymphoma } \\
\text { Acute Budd-Chiari Syndrome } \\
\text { Nodular Regenerative Hyperplasia } \\
\text { Unknown }\end{array}$ & $\begin{array}{c}21 \\
1 \\
2 \\
3 \\
2 \\
4 \\
2 \\
2 \\
1 \\
4\end{array}$ & 15 \\
\hline
\end{tabular}


Table 2. Characteristics of the patients according to the indication for RLT

\begin{tabular}{|c|c|c|c|c|c|c|}
\hline$N=143$ & $\begin{array}{c}\text { ITBL } \\
\text { (N=33) }\end{array}$ & $\begin{array}{c}\text { PNF } \\
(N=29)\end{array}$ & $\begin{array}{c}\text { HAT } \\
(\mathrm{N}=25)\end{array}$ & $\begin{array}{l}\text { Rejection } \\
(\mathrm{N}=\mathbf{2 4})\end{array}$ & $\begin{array}{l}\text { Recurrence } \\
\qquad(\mathrm{N}=11)\end{array}$ & $\begin{array}{l}\text { Other } \\
(\mathrm{N}=21)\end{array}$ \\
\hline Gender F/M & $11 / 22$ & $14 / 15$ & $6 / 19$ & $6 / 15$ & $5 / 6$ & $8 / 13$ \\
\hline Mean age at LT [yrs] & $37+/-17$ & $45+/-12$ & $40+/-15$ & $35+/-18$ & $48+/-13$ & $40+/-19$ \\
\hline Mean age at RLT [yrs] & $41+/-14$ & $45+/-12$ & $40+/-14$ & $39+/-14$ & $50+/-14$ & $46+/-12$ \\
\hline Interval LT-RLT [yrs] & $3,9+/-5,9$ & $0,03+/-0,08$ & $0,44+/-1,4$ & $3,4+/-5,0$ & $2,13+/-2,2$ & $6,4+/-8,5$ \\
\hline Follow-up after RLT [yrs] & $5.4+/-4.9$ & $3.9+/-5.4$ & $5.2+/-6.1$ & $4.0+/-5.6$ & $1.9+/-4.0$ & $1.6+/-2.7$ \\
\hline Mortality at 90 days & $9 \%(3)$ & $45 \%(13)$ & $32 \%(8)$ & $29 \%(7)$ & $55 \%(6)$ & $43 \%(9)$ \\
\hline Mean donor age & $41+/-14$ & $39+/-15$ & $36+/-16$ & $43+/-18$ & $49+/-17$ & $46+/-19$ \\
\hline Donor CMV + & $51 \%(17)$ & $48 \%(14)$ & $36 \%(9)$ & $37 \%(9)$ & $18 \%(2)$ & $47 \%(10)$ \\
\hline $\begin{array}{l}\text { Initial disease : } \\
\text { Autoimmune cirrhosis }\end{array}$ & $3 \%(1)$ & $3 \%(1)$ & $4 \%(1)$ & $0 \%(0)$ & $0 \%(0)$ & $0 \%(0)$ \\
\hline Hepatocellular carcinoma & $12 \%(4)$ & $14 \%(4)$ & $16 \%(4)$ & $12 \%(3)$ & $27 \%(3)$ & $29 \%(6)$ \\
\hline Hepatitis B cirrhosis & $6 \%(2)$ & $10 \%(3)$ & $8 \%(2)$ & $12 \%(3)$ & $9 \%(1)$ & $5 \%(1)$ \\
\hline Hepatitis C cirrhosis & $12 \%(4)$ & $17 \%(5)$ & $16 \%(4)$ & $29 \%(7)$ & $45 \%(5)$ & $14 \%(3)$ \\
\hline Alcohol-related cirrhosis & $15 \%(5)$ & $21 \%(6)$ & $16 \%(4)$ & $12 \%(3)$ & $0 \%(0)$ & $19 \%(4)$ \\
\hline Fulminant hepatitis & $3 \%(1)$ & $7 \%(2)$ & $4 \%(1)$ & $8 \%(2)$ & $9 \%(1)$ & $10 \%(2)$ \\
\hline Metabolic liver disease & $12 \%(4)$ & $0 \%(0)$ & $4 \%(1)$ & $4 \%(1)$ & $0 \%(0)$ & $5 \%(1)$ \\
\hline Biliary disease & $24 \%(8)$ & $7 \%(2)$ & $24 \%(6)$ & $17 \%(4)$ & $9 \%(1)$ & $10 \%(2)$ \\
\hline Other & $12 \%(4)$ & $21 \%(6)$ & $8 \%(2)$ & $4 \%(1)$ & $0 \%(0)$ & $10 \%(2)$ \\
\hline Dialysis before RLT & $6 \%(2)$ & $28 \%(8)$ & $12 \%(3)$ & $8 \%(2)$ & $18 \%(2)$ & $33 \%(7)$ \\
\hline Ventilation before RLT & $9 \%(3)$ & $72 \%(21)$ & $28 \%(7)$ & $12 \%(3)$ & $18 \%(2)$ & $38 \%(8)$ \\
\hline $\begin{array}{l}\text { Transfusion during RLT } \\
\text { (packed red blood cells) }\end{array}$ & $11.4+/-13.7$ & $7.3+/-4.7$ & $16.7+/-33.4$ & $10.5+/-7.9$ & $17.4+/-10.6$ & $13.9+/-15.8$ \\
\hline
\end{tabular}


Table 3. Evolution over time of the characteristics of the patients at and after RLT

\begin{tabular}{|c|c|c|c|c|c|}
\hline & $\mathrm{N}$ & $\begin{array}{c}\text { P1 (1987-1994) } \\
N=48\end{array}$ & $\begin{array}{c}\text { P2 (1995-2004) } \\
N=43\end{array}$ & $\begin{array}{c}\text { P3 (2005-2011) } \\
N=52\end{array}$ & $\mathrm{p}$ \\
\hline Mortality at 90 days & 143 & $36 \%$ & $28 \%$ & $33 \%$ & NS \\
\hline Mortality at 1 year & 143 & $46 \%$ & $33 \%$ & $42 \%$ & NS \\
\hline Mortality at 5 years & 143 & $59 \%$ & $35 \%$ & $48 \%$ & NS \\
\hline Donor age (median, years, interval) & 131 & $37(23-51)$ & $40(23-57)$ & $46(30-62)$ & 0.02 \\
\hline Donor CMV positive & 114 & $16(55 \%)$ & $20(54 \%)$ & $25(52 \%)$ & NS \\
\hline Recipient CMV positive & 119 & $30(86 \%)$ & $25(69 \%)$ & $34(71 \%)$ & NS \\
\hline Median Cold ischemia time ( $\mathrm{min})$ & 139 & $551(320-782)$ & $580(430-730)$ & $501(344-658)$ & 0.09 \\
\hline Interval between LT and RLT (days) & 143 & $14(5-161)$ & $132(12-852)$ & $228(21-3649)$ & $<0.001$ \\
\hline Indications for RLT & 143 & & & & 0.016 \\
\hline ITBL & 33 & $5(10 \%)$ & $13(30 \%)$ & $15(29 \%)$ & \\
\hline PNF & 29 & $15(31 \%)$ & $8(19 \%)$ & $6(12 \%)$ & \\
\hline HAT & 25 & $9(19 \%)$ & $10(23 \%)$ & $6(12 \%)$ & \\
\hline Rejection & 24 & $11(23 \%)$ & $6(14 \%)$ & $7(13 \%)$ & \\
\hline Recurrence & 11 & $4(8 \%)$ & 0 & $7(13 \%)$ & \\
\hline Other & 21 & $4(8 \%)$ & $6(14 \%)$ & $11(21 \%)$ & \\
\hline Biliary anastomosis & 123 & & & & 0.05 \\
\hline Roux-in-Y & & $29(78 \%)$ & $25(64 \%)$ & $25(53 \%)$ & \\
\hline Duct-to-duct & & $8(22 \%)$ & $14(36 \%)$ & $22(47 \%)$ & \\
\hline Caval anastomosis & 126 & & & & 0.003 \\
\hline End-to-end & & $37(100 \%)$ & $32(80 \%)$ & $35(71 \%)$ & \\
\hline Piggyback & & 0 & $8(22 \%)$ & $14(29 \%)$ & \\
\hline Immunosuppressive regimen & 98 & & & & 0.001 \\
\hline Ciclosporine & & $12(46 \%)$ & $6(18 \%)$ & $9(23 \%)$ & \\
\hline Tacrolimus & & $2(8 \%)$ & $22(67 \%)$ & $28(72 \%)$ & \\
\hline Other & & $12(46 \%)$ & $5(15 \%)$ & $2(5 \%)$ & \\
\hline
\end{tabular}


Table 4. Univariate and multivariate analyses of factors influencing survival after RLT

\begin{tabular}{|c|c|c|c|c|c|c|}
\hline \multirow[t]{2}{*}{ Patient characteristics } & \multicolumn{3}{|c|}{ Univariate analysis } & \multicolumn{3}{|c|}{ Multivariate analysis } \\
\hline & $\begin{array}{l}\text { Hazard } \\
\text { ratio }\end{array}$ & $\underline{95 \% \mathrm{Cl}}$ & $p$ & $\begin{array}{l}\text { Hazard } \\
\text { ratio }\end{array}$ & & $\mathbf{p}$ \\
\hline $\begin{array}{l}\text { Time to first RLT } \\
\quad>90 \text { days } \\
8 \text { to } 90 \text { days } \\
<7 \text { days }\end{array}$ & $\begin{array}{l}\underline{1} \\
\underline{1.3} \\
\underline{1.6}\end{array}$ & & $\underline{0.26}$ & $=$ & & \\
\hline $\begin{array}{l}\text { Donor-recipient } \\
\text { Sex mismatch }\end{array}$ & $\underline{1.5}$ & {$[0.95,2.3]$} & $\underline{0.08}$ & $=$ & & \\
\hline Donor age $>40 y$ & $\underline{1.0}$ & {$[0.6,1.7]$} & $\underline{0.88}$ & $=$ & & \\
\hline $\mathrm{CMV}+(\mathrm{R}$ or $\mathrm{D})$ & $\underline{3.5}$ & {$[1.1,11.3]$} & 0.04 & $=$ & & \\
\hline Ventilation & $\underline{1.6}$ & {$[0.96,2.7]$} & $\underline{0.07}$ & $=$ & & \\
\hline $\begin{array}{l}\text { Red blood cell } \\
\text { transfusion (>7 units) }\end{array}$ & $\underline{2.0}$ & {$[1.2,3.4]$} & $\underline{0.006}$ & $\underline{1.7}$ & $\underline{1.1,2.7}$ & $\underline{0.02}$ \\
\hline Cold ischemia (>12h) & $\underline{1.2}$ & {$[0.7,2.1]$} & $\underline{0.56}$ & $=$ & & \\
\hline Veno-venous bypass & $\underline{1.5}$ & {$[0.9,2.4]$} & $\underline{0.09}$ & $=$ & & \\
\hline Dialysis & $\underline{2.4}$ & {$[1.3,4.2]$} & $\underline{0.005}$ & $\underline{1.9}$ & $\underline{1.1,3.1}$ & $\underline{0.02}$ \\
\hline $\begin{array}{l}\text { Time period } \\
1987 \text { to } 1994 \text { (P1) } \\
1995 \text { to } 2004 \text { (P2) } \\
2005 \text { to } 2011 \text { (P3) }\end{array}$ & $\begin{array}{l}\underline{1} \\
\underline{0.6} \\
\underline{0.7} \\
\end{array}$ & & 0.22 & $=$ & & \\
\hline $\begin{array}{l}\text { Indication for RLT } \\
\text { ITBL } \\
\text { HAT+PNF } \\
\text { Others }\end{array}$ & $\frac{\frac{1}{2.0}}{\underline{2.5}}$ & & $\underline{0.015}$ & $=$ & & \\
\hline
\end{tabular}


Table 5. Surgical complications and treatments after RLT ( $n=143)$

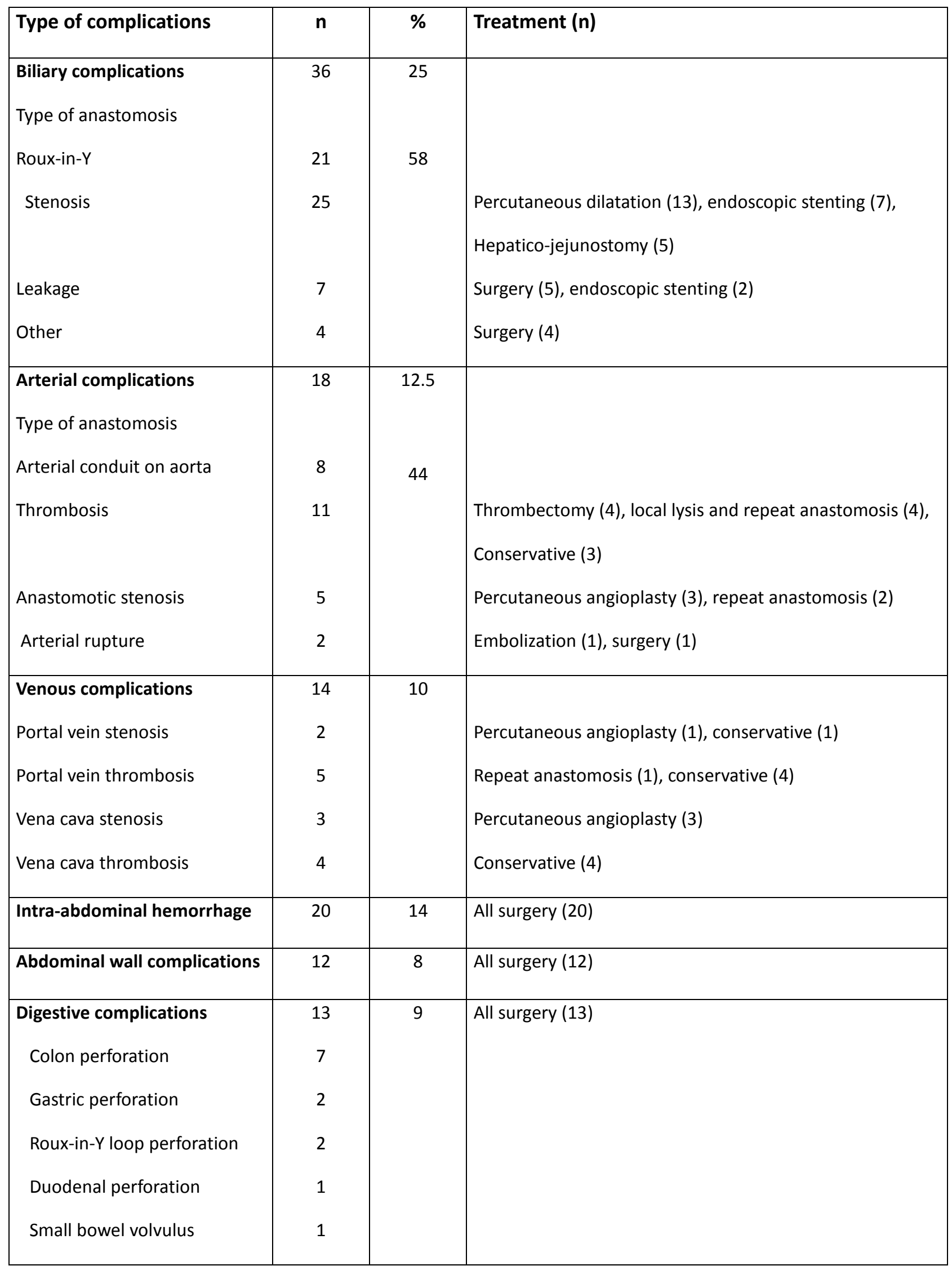


Fig. 3. Kaplan-Meier survival analysis according to initial severity (Severe: dialysis and/or ventilation, dashed vs. non severe, plain).

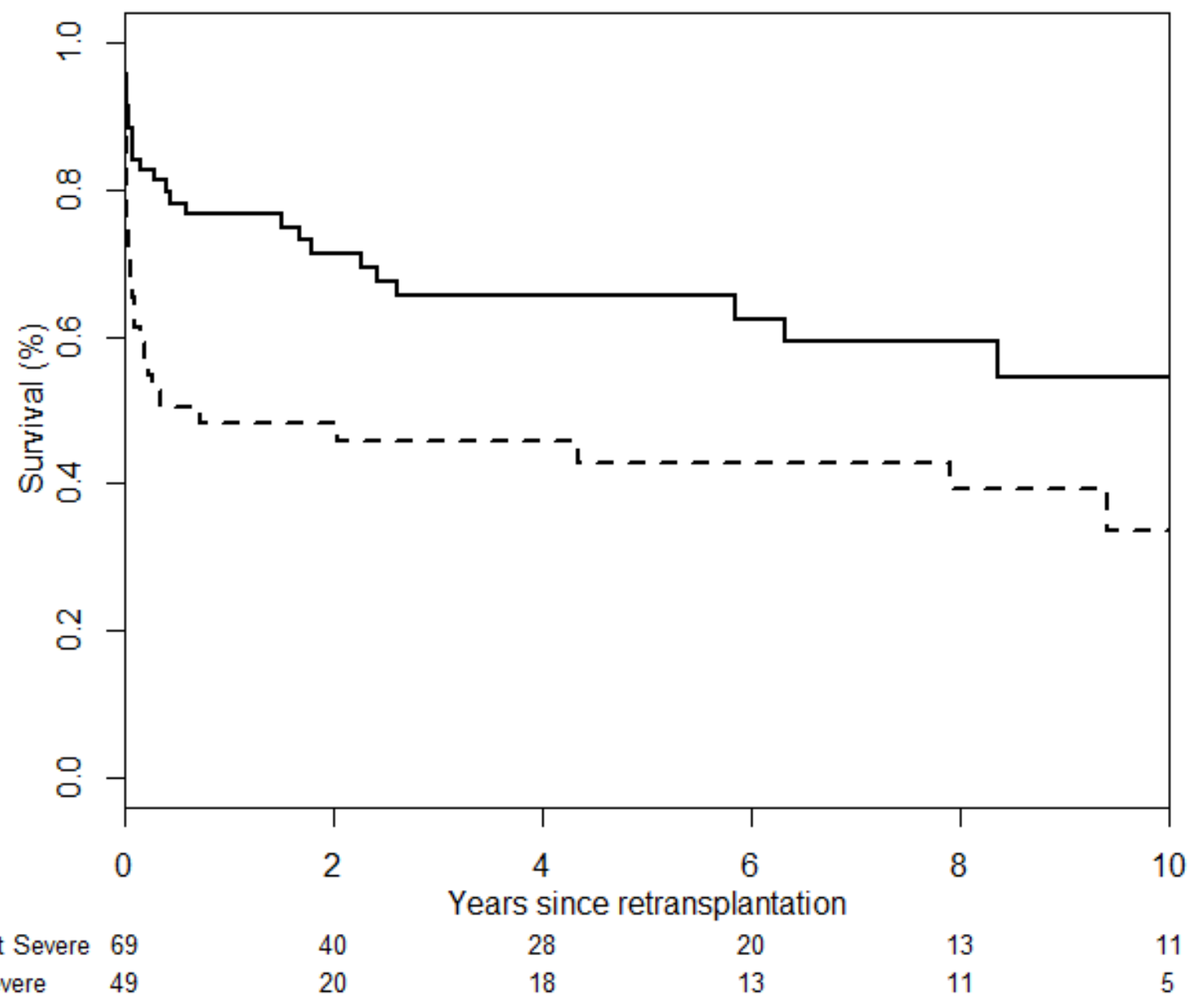


Fig. 3. Kaplan-Meier survival analysis according to initial severity (Severe: dialysis and/or ventilation, dashed vs. non severe, plain).

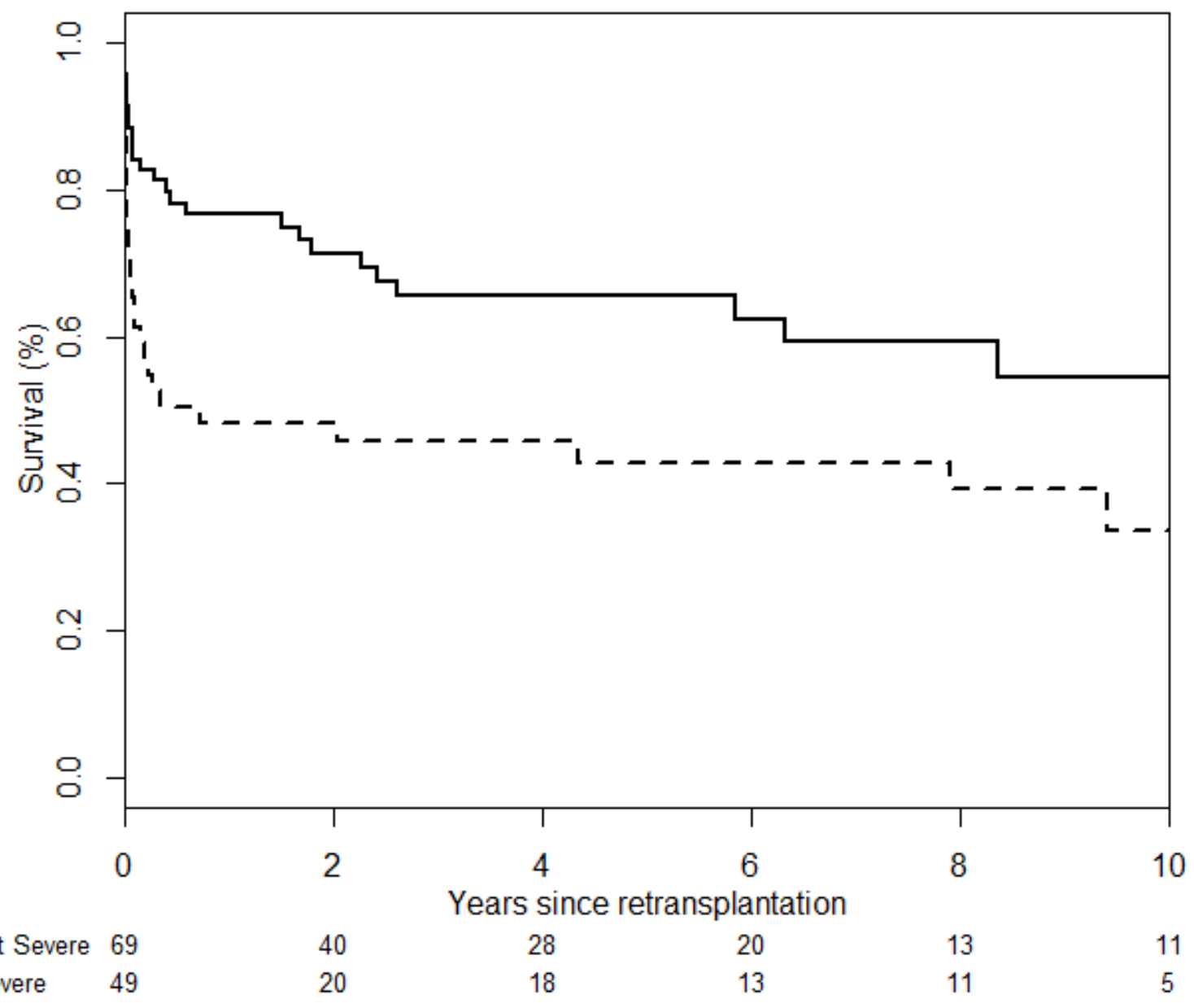


Fig. 3. Kaplan-Meier survival analysis according to initial severity (Severe: dialysis and/or ventilation, dashed vs. non severe, plain).

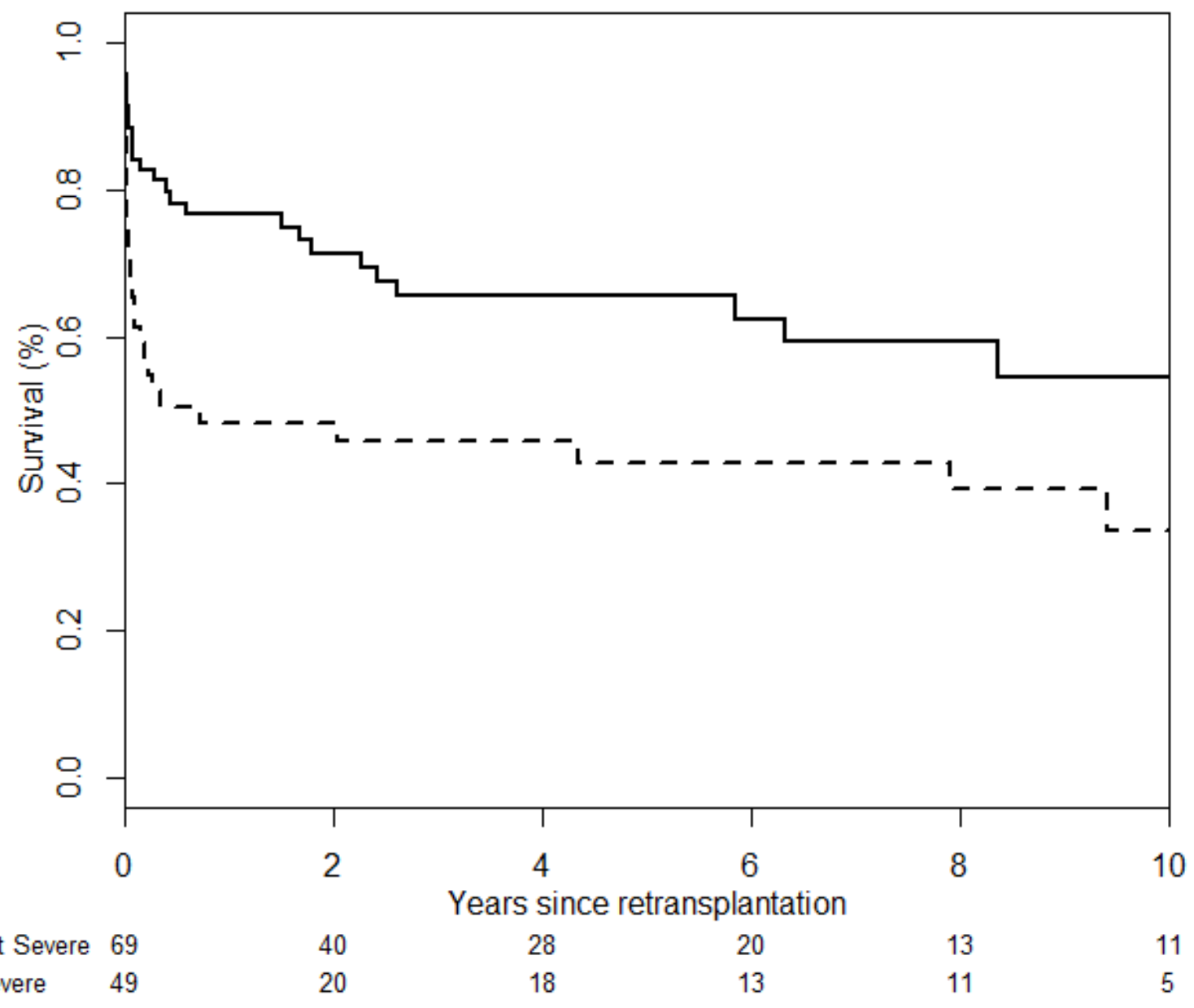

